\title{
Juventudes, definición y autorreflexión
}

Youth, definition and self-reflection

Juventude, definição e autorreflexão

Anna María Fernández Poncela

Universidad Autónoma Metropolitana, México

fpam1721@correo.xoc.uam.mx

https://orcid.org/0000-0003-3080-212X

\section{Resumen}

El objetivo fue conocer la definición y percepción que tanto un grupo de jóvenes como de adultos tienen en torno al concepto juventud (o juventudes) para luego establecer similitudes y diferencias entre ambas concepciones. Para ello, se efectuaron entrevistas a jóvenes (cuyas edades oscilaban entre los 18 y los 29 años) y a personas adultas (mayores de 40 años). La entrevista diseñada fue aplicada a 80 personas (40 mujeres y 40 hombres). La mitad de los informantes estuvo conformada por jóvenes de entre 18 y 29 años, y la otra mitad por mayores de 40 años. Los participantes en este estudio fueron personas residenciadas en zonas urbanas de la ciudad de México durante la primavera del año 2019, con diferentes niveles educativos, de ingreso y ocupaciones. Los resultados de muestran que para un alto porcentaje de los consultados — independientemente de si eran jóvenes o adultos, mujeres u hombresla mayoría de la juventud actual está "perdida” y “desorientada”. Sin embargo, cuando se les consultó sobre la definición de ser joven aparecieron expresiones sobre las oportunidades ante la vida presente y futura. En este sentido, el grupo de jóvenes hizo hincapié en la posibilidad de hacer cosas y tener energía, mientras que el de los adultos agregó palabras vinculadas con los sueños, la alegría y lo bonito (adjetivo usado por las mujeres), lo que deja entrever cierto grado de recuerdo y una suerte de melancolía por esa época. En definitiva, se 


\title{
Revista Iberoamericana \\ de las Ciencias Sociales y Humanísticas
}

ISSN: $2395-7972$

pude decir que si bien algunas opiniones recabadas fueron contradictorias, todas representan una muestra de las ambivalencias que emergen en torno al concepto juventud.

Palabras clave: México, miradas, percepciones, problemas, reflexiones, ventajas.

\begin{abstract}
The objective was to know the definition and perception that both a group of young people and adults have regarding the concept of youth and then establish similarities and differences between both conceptions. To do this, interviews were conducted with young people (whose ages ranged from 18 to 29 years old) and adults (over 40 years old). The designed interview was applied to 80 people (40 women and 40 men). Half of the informants were made up of young people between 18 and 29 years old, and the other half were over 40 years old. The participants in this study were people residing in urban areas of Mexico City during the spring of 2019, with different levels of education, income and occupations. The results show that for a high percentage of those consulted - regardless of whether they were young or old, women or men - the majority of today's youth are "lost" and "disoriented". However, when they were consulted about the definition of being young, expressions about the opportunities in the present and future life appeared. In this sense, the youth group emphasized the possibility of doing things and having energy, while the adult group added words related to dreams, joy and beauty (an adjective used by women), which suggests a certain degree of memory and a kind of melancholy at that time. In short, it can be said that although some opinions gathered were contradictory, they all represent a sample of the ambivalences that emerge around the concept of youth.
\end{abstract}

Keywords: Mexico, look, perceptions, problems, reflections, advantages.

\section{Resumo}

Muito se fala e se investiga sobre a juventude. Aqui é feita uma abordagem a eles de acordo com suas percepções, definições e reflexões, bem como, a partir da perspectiva dos adultos, a fim de contrastar visões. Em um primeiro momento, é feita uma revisão da literatura sobre o assunto, ou seja, da academia. Em segundo lugar, as entrevistas que expressam definições e autodefinições são apresentadas e analisadas. Trata-se de um estudo exploratório com 


\section{Revista Iberoamericana de las Ciencias Sociales y Humanísticas}

abordagem qualitativa que busca as vozes e visões das pessoas sobre como vêem os jovens, o que significa ser jovem, os problemas e vantagens da juventude.

Como resultado é possível afirmar que ser joven en abstracto es considerado algo positivo por toda a población consultada, sem embargo, existe uma mirada negativa hacia la juventud real, desde jóvenes e adultos, y además ser joven tiene sus aspectos ventajosos, y también sus cuestiones problemáticas.

Palavras-chave: percepções, pontos de vista, problemas, vantagens, reflexões, México.

Fecha Recepción: Junio 2020

Fecha Aceptación: Diciembre 2020

\section{Introducción}

En este texto, básicamente, se recogen testimonios de jóvenes en torno a la definición y a las implicaciones del concepto juventud. Para ello, se parte de la concepción de que esa palabra es un constructo sociocultural y de composición heterogénea ubicado en un contexto espacio-temporal. Asimismo, se considera que en la actualidad se habla de juventudes (en plural $^{1}$ ) construidas históricamente, las cuales incluyen diferentes formas de ser y distintas relaciones de poder social, como proceso múltiple y dinámico que tiene lugar entre personas, colectivos, sexos, generaciones, etc. (Duarte, 2000; Margulis y Urresti, 2008; Villa, 2011).

En los últimos decenios, el estudio de las juventudes ha cobrado fuerza e interés, si bien en otras épocas era un área condenada prácticamente a la invisibilidad o a la desvalorización. Ser joven, de hecho, se ha convertido en una identidad que está de moda, la cual se procura conservar y proyectar como una actitud ante la vida, aunque vale acotar que, por otra parte, también se asocia a diversos problemas que preocupan a la humanidad, como desempleo, crisis de valores, adicción a drogas ilegales, inseguridad ciudadana, violencia, delincuencia, etc. (Feixa, 1993; Passerini, 1996). En otras palabras, es un concepto en la cual puede subyacer tanto lo ideal como lo negativo de una misma realidad. Es una metáfora, una subcultura o un subsistema donde convergen distintas miradas, las cuales suelen ser estudiadas desde múltiples perspectivas — p. ej., desde la biología, la psicología, etc. (Reguillo, 2010; Valenzuela, 2009)_, que lastimosamente se suelen enfocar en una percepción de víctimas de la sociedad actual del sistema capitalista y neoliberal (Beck, 2006).

${ }^{1}$ Del concepto joven o jóvenes se pasó a juventud, y hoy a juventudes (Sepúlveda, 2011). 


\section{Revista Iberoamericana \\ de las Ciencias Sociales y Humanísticas}

ISSN: $2395-7972$

A grandes rasgos, se puede decir que tanto en el imaginario cultural general como en el marco intelectual particular se identifica a la juventud como una etapa de la vida ubicada, generalmente, entre el periodo de la educación secundaria y la educación superior, es decir, en un rango de edad que oscilaría entre los 15 y los 24 años (Organización de las Naciones Unidas [ONU], (2020), o entre los 12 y los 29 años (Instituto Mexicano de la Juventud [IMJ], 2017). Sin embargo, distintos autores sostienen que la concepción de dicho término incluye otras variables (además de la temporal), especialmente si se analiza desde un enfoque sociohistórico y político-cultural (Margulis y Urresti, 2008; Reguillo, 2010; Urteaga, 2011; Valenzuela, 2009), de ahí que se pueda afirmar que no existe unanimidad en torno a la concepción de ese periodo.

Por ese motivo, el objetivo de la presente investigación fue conocer la definición y percepción que tanto un grupo de jóvenes como de adultos tienen en torno al concepto juventud (o juventudes) para luego establecer similitudes $\mathrm{y}$ diferencias entre ambas concepciones.

\section{Método}

En el presente documento se ofrece un estudio exploratorio cualitativo que en antropología se denomina émic, perspectiva que se basa en el análisis de un fenómeno según la visión de los propios protagonistas. En el proceso se ha empleado el enfoque de los campos semánticos (Pérez, 2015), el cual se basa en analizar un conjunto de palabras y expresiones sobre un concepto.

En concreto, se efectuaron entrevistas a jóvenes (cuyas edades oscilaban entre los 18 y los 29 años) y a personas adultas (mayores de 40 años) para indagar en el significado que para ellos tiene la juventud; luego las respuestas fueron contrastadas para formar una visión holística del objeto de estudio.

El grupo de jóvenes fue elegido a partir de los 18 años (mayores de edad) para evitar tener problemas legales a la hora de realizar las entrevistas; la edad límite de 29 años se consideró según lo referido por diversos autores.

La entrevista diseñada fue aplicada a 80 personas (40 mujeres y 40 hombres). La mitad de los informantes estuvo conformada por jóvenes de entre 18 y 29 años, y la otra mitad por mayores de 40 años. Vale acotar que generalmente se realizan estudios con jóvenes de clase media que viven en la ciudad, por lo que son ignorados aquellos que viven en zonas 


\section{Revista Iberoamericana \\ de las Ciencias Sociales y Humanísticas}

ISSN: $2395-7972$

más alejadas, sin educación y en condiciones desventajosas. Los participantes en este estudio, sin embargo, eran personas residenciadas en zonas urbanas de la ciudad de México durante la primavera del año 2019, con diferentes niveles educativos, de ingreso y ocupaciones.

A continuación se ofrecen algunas de la principales variables sociodemográficas de los participantes: entre el grupo de jóvenes la media de edad fue de 22 años y la moda de 21 años, mientras que entre los adultos la media fue de 54.25 años y la moda de 40 años. En cuanto a los jóvenes, $97.7 \%$ eran solteros y 1 viudo; 90 \% sin hijos y $10 \%$ con hijos. Entre los mayores, $40 \%$ eran casados, $7.5 \%$ viudos, $17 \%$ solteros y $10 \%$ en unión libre; $35 \%$ no tenían hijos, mientras que los demás tenían entre uno y ocho hijos (dos hijos fue la cantidad más repetida).

El nivel educativo de los jóvenes era el siguiente: $65 \%$ cursaban o habían culminado el bachillerato, $17.5 \%$ estudiaban una licenciatura o la habían concluido, $17.5 \%$ llegaron a secundaria. En cuanto a los adultos, $5 \%$ contaba con posgrado, $25 \%$ licenciatura, $40 \%$ bachillerato, $15 \%$ primaria, $10 \%$ secundaria, $2.5 \%$ una carrera comercial, y $2.5 \%$ sin estudios, lo cual indica un mayor nivel educativo para los de menor edad.

En lo concerniente a la ocupación de los jóvenes, $52.5 \%$ eran estudiantes, $40 \%$ empleados, $5.5 \%$ amas de casa, $2.5 \%$ servicio social, $2.5 \%$ músicos, mientras que $42.5 \%$ de los mayores trabajaban como empleados, $22.5 \%$ como trabajadores del área doméstica, $15 \%$ comerciantes, $10 \%$ jubilados, $2.5 \%$ empleados independientes, $2.5 \%$ licenciados en derecho, $2.5 \%$ en administradora y $2.5 \%$ en hotelería.

Sobre los ingresos, $82.5 \%$ de los jóvenes se ubicaron en el rango medio, $12.5 \%$ en bajo y $2.5 \%$ en alto (2.5\% no contestó). Por su parte, $70 \%$ de las personas adultas se ubicaron en medio, $27.5 \%$ en bajo y $2.5 \%$ no respondió.

\section{Una definición desde los investigadores sociales}

Como se dijo, la juventud es una construcción social y, principalmente, una identidad personal (Lozano, 1991). Es una etapa biográfica constituida socialmente que va de la infancia y la pubertad fisiológica a la edad adulta, según concepciones actuales. Para algunos autores, este constituye un periodo de transición de la familia a la sociedad. Una especie de inversión — a veces festiva y otras dramática—, donde la persona se sitúa mientras accede al mundo considerado adulto: una especie de vestíbulo, interregno o sala de espera de la cual 


\section{Revista Iberoamericana de las Ciencias Sociales y Humanísticas}

únicamente se sale con el paso del tiempo (Cardús y Estruch, 1992; Martínez y Berney, 1991).

Para diversos autores, los jóvenes, como actores sociales, conforman un universo social discontinuo y cambiante; sus características son fruto de una suerte de negociacióntensión entre la categoría sociocultural asignada por la sociedad particular y la actualización subjetiva que sujetos concretos llevan a cabo a partir de la interiorización diferenciada de los esquemas de la cultura vigente (Reguillo, 1997). Los jóvenes, en cambio, perciben diferencias entre ellos, similares a las que distinguen a personas de cualquier edad (Martín Serrano, 1991). En pocas palabras, existen múltiples definiciones para intentar entender este constructo (todas válidas), y a medida que pasa el tiempo se van afinando e integrando nuevos enfoques basados en el paradigma académico de cada época.

Aun así, en definitiva pareciera tratarse, por un lado, de la identidad que los jóvenes tienen consigo mismos y la identidad con los adultos (Martín Serrano, 1991). Es un proceso de observación, reflexión, construcción y afirmación de identidad. Por eso, se habla también de la dolorosa crisis de identidad normativa, tránsito necesario para el acceso a la edad adulta, crisis de la intimidad, sentimiento de aislamiento y confusión de la idea que el adolescente se hace de sí mismo, y cómo la sociedad no lo acompaña proporcionando modelos plausibles.

Esto en el contexto de la sociedad occidental (Mead, 1945), donde la adolescencia y la juventud han sido visionadas como etapas intermedias de cambio y, especialmente, de tránsito (Erikson, 1972, 1985). Esta visión, si bien se considera clásica y conservadora (Duarte, 2000), no deja de ser acertada y estar presente, lo cual también sucede con la consideración contemporánea del agenciamiento cultural y social de las juventudes, esto es, su rol activo en la construcción de sus vidas. Además de los estudios sociales de las juventudes "en sus propios términos", como productoras de discursos y prácticas, a través de su propia mirada (Urteaga, 2011).

La juventud, por tanto, es un concepto complejo que merece mayor reflexión, de ahí la dificultad que subyace en todo intento de teorización (Erikson, 1972). En efecto, "el problema de la juventud" es una problemática joven (valga la redundancia), ya que se considera como un fenómeno moderno y reciente (Cardús y Estruch, 1992). La juventud entendida como en la actualidad - tiene apenas un par de centurias (Ariès, 1962), lo cual también sucede con la infancia, la adolescencia y la conformación de la familia moderna, con aires de liberalismo e ilustración. 


\section{Revista Iberoamericana de las Ciencias Sociales y Humanísticas}

Es cierto que en otros periodos históricos no se ignoraba el fenómeno juvenil, aunque no se tenía tan en cuenta como en la historia reciente (Souto, 2007). En este sentido, Rousseau (1972) es considerado uno de los precursores del análisis de estas etapas, mientras que en el caso de la adolescencia esta se consolida en el siglo XX (Hall, 1904) como etapa de crisis previa a la adultez.

Lo que interesa dejar claro es que no hay una problemática de la juventud per se. El llamado "problema de la juventud" y el paso a la edad adulta deben de analizarse desde la perspectiva de los conflictos sociales que impregnan a las instituciones, entre ellas a la escuela (Coleman y Husén, 1989), la familia, el empleo, la política, la sexualidad, los medios, el ocio y el tiempo libre, por ejemplo. Al respecto, Lechner (2004) señala: "La cultura juvenil es parte de la convivencia social. Los jóvenes no tienen una 'subcultura' aparte, escindida de la sociedad, sino que comparten — con modalidades específicas — las maneras prácticas de convivir" (p. 25).

Resumiendo, la juventud podría ser la contraparte social del concepto psicológico de la adolescencia, así como del concepto biológico de pubertad, si bien la adolescencia hoy día es también considerada una fase intermedia entre infancia y juventud. Es una condición biológica en el sentido de que responde a un proceso de maduración individual — según se afirma en la abundante bibliografía al respecto-. Además, se trata de un estado psicológico porque define un estadio de la vida determinado por procesos endógenos que forman la denominada personalidad adulta. Por otra parte, es un grupo de edad, un conjunto de individuos definidos cronológicamente y que, por ello, comparten determinados aspectos sociales. Esto, si bien ha sido criticado y relativizado (Reguillo 2010; Urteaga, 2011), no deja de ser parte de la realidad social para la educación o la política y para la gente en general, pues la juventud es una etapa de desarrollo psicobiológico humano, un momento de integración social, un dato sociodemográfico, a veces agente de cambio y en otras un problema de desarrollo. En pocas palabras, un estado mental, un estilo de consumo cultural, un fenómeno de carácter procesual (Fernández, 2003). Una generación y representación de un conjunto de individuos nacidos en fechas similares, los cuales comparten experiencias históricas parecidas.

Como construcción sociocultural, la juventud es fruto de la interacción de las condiciones sociales y las imágenes culturales que cada grupo o sector elabora en cada momento histórico sobre un grupo de edad (entendiendo por condiciones sociales al conjunto 


\section{Revista Iberoamericana de las Ciencias Sociales y Humanísticas}

de prácticas institucionales, derechos y obligaciones que configuran las conductas y oportunidades de los jóvenes que conforman la situación estructural de la juventud, y por imágenes culturales el complejo de atributos ideológicos y de valores adjudicados a los jóvenes en cada momento y al universo simbólico que constituye su mundo material e inmaterial, resultado de elaboraciones subjetivas de los propios jóvenes) (Feixa, 1993; Passerini, 1996).

En el caso de México, las investigaciones sobre la juventud han girado en los últimos tiempos en torno a perspectivas sectoriales y sobre grupos específicos bajo el enfoque de estilos y culturas, aunque en cuanto al tema que nos interesa en estas páginas, la reflexión no ha sido tan afortunada. Reguillo (2010) apunta tres etapas en torno a la emergencia del actor político juvenil en México: el estudiantado del 68, la emergencia del joven popular urbano (las bandas), y el surgimiento de las culturas juveniles a finales de los años ochenta. Esta autora también considera que hay dos juventudes en el país: una mayoritaria precarizada, desconectada y desafiliada, y otra minoritaria, conectada, incorporada a instituciones sociales.

Para concluir este punto, vale comentar en cuál grupo de edad se ubicarían los jóvenes. Al respecto, y más allá de la discusión teórica y académica sobre el tema, hay una cuestión de carácter social y práctico²: por una parte, el Instituto Nacional de Estadística y Geografía (Inegi) y la ONU estiman que ese rango de edad se ubica entre los 15 y 29 años, mientras que el IMJ lo establece en los 12 y los 29 años. Para ser más precisos, la definición de la población joven en función de su edad puede establecerse en tres grupos etarios: de los 14 a los 19, de los 19 a los 24 y de los 24 a los 29 (Welti, 1996).

Hoy en México los jóvenes constituyen un importante peso en la pirámide demográfica del país. De hecho, la población joven mexicana supera a la del resto de los países latinoamericanos e incluso a la de Estados Unidos. Según la encuesta intercensal del Inegi (2015), había 119530743 millones de habitantes en el país, y 37.5 millones de jóvenes

\footnotetext{
2 “¿Cómo enfoca el sociólogo el problema de los jóvenes? El reflejo profesional del sociólogo es señalar que las divisiones entre las edades son arbitrarias. Es la paradoja de Pareto, cuando dice que no se sabe a qué edad empieza la vejez igual que no se sabe dónde empieza la riqueza. De hecho, la frontera entre juventud y vejez en todas las sociedades es objeto de lucha" (Bourdieu 1984, p. 163). Este autor sostiene que cuando se colocan bajo un mismo concepto universos sociales que nada tienen en común, se trata de un abuso del lenguaje. Y tiene indudablemente razón, sin embargo, esto es debido a la abstracción para poder analizar e interpretar, y se hace con mujeres, indígenas, obreros, etc. También comenta que hablar de jóvenes como un grupo de intereses comunes es una manipulación.
} 
de entre 12 y 29 años, lo que representa $31.4 \%$ de la población mexicana. De los 20 a los 29 años hay 20 millones de personas.

Según el Consejo Nacional de Evaluación de la Política de Desarrollo Social (Coneval) (2018) y el Consejo Nacional para Prevenir la Discriminación (Conapred) (2018), la mitad de la población joven vive en condiciones de pobreza, la cual es discriminada por una diversidad de factores etarios, sociales, étnicos, educativos, etc. (Salas y De Oliveira, 2014). En síntesis, los jóvenes no son la enajenación total atribuida ni el potencial transformador innato atribuido (Ulloa, 2016), como se espera demostrar a lo largo de estas páginas.

\section{Resultados y discusión}

\section{Autopercepción juvenil y perspectiva de los adultos}

En este apartado se enseñan y analizan las opiniones los entrevistados, para lo cual se revisa la frecuencia en que aparecen ciertos vocablos y campos semánticos. Si bien la presente es considerada una investigación cualitativa, se optó también por cuantificar las expresiones positivas y negativas de algunas de las respuestas recabadas. Luego se ahondó en el repertorio de unidades léxicas vinculadas en una asociación semántica. Las expresiones se redujeron a una palabra o a una mínima agrupación con sentido, y se ordenaron de mayor a menor según la frecuencia.

\section{¿Cómo ve usted a la juventud?}

En primer lugar, se pude afirmar que tanto los jóvenes como la población adulta tienen percepción negativa en torno a la juventud (tabla 1). 
Revista Iberoamericana

de las Ciencias Sociales y Humanísticas

Tabla 1. Cómo ve a la juventud hoy

\begin{tabular}{|l|c|c|c|c|}
\hline & \multicolumn{2}{|c|}{$18-29$} & +40 \\
\hline & HOMBRES & MUJERES & HOMBRES & MUJERES \\
\hline & & & & \\
\hline Negativa & 13 & 13 & 15 & 16 \\
\hline Positiva & 3 & 0 & 2 & 0 \\
\hline $\begin{array}{l}\text { Negativa } \\
\text { positiva }\end{array}$ & 4 & 3 & 3 & 2 \\
\hline Neutra & 0 & 4 & 0 & 2 \\
\hline Totales & 20 & 20 & 20 & 20 \\
\hline TOTAL & & 40 & & 40 \\
\hline
\end{tabular}

Fuente: Elaboración propia

Como se observa, predomina una visión negativa en los encuestados, lo cual es un poco más acentuado en las personas mayores. Esa visión pesimista tiene que ver con palabras como las siguientes: "perdida" y "desubicada", “errática” y "sin rumbo", “desorientada" y "confundida".

En concreto, algunos jóvenes consideran que "no saben qué quieren”. De forma más específica, un joven indicó que este grupo de personas “están fuera de la realidad”, y una joven indicó que era una generación "poco soñadora". Otras palabras usadas son "desinterés", “despreocupación”, "indiferencia”, "pésima”, "descarriada” e incluso "podrida", así como "sin valores" y "sin respeto".

La población adulta conformada por hombres, por su parte, señala que esa generación está “perdida", en especial por la "tecnología", pues está "metida en el mundo digital”, esta postura sobre todo por hombres. También destacan su falta de "interés” y "confusión”, "falta de conciencia". Incluso que son "flojos", "no quieren hacer nada", "sienten que merecen todo y no hacen esfuerzo". Las mujeres adultas, en cambio, subrayan la "falta de educación" y el "irrespeto" por los mayores y los valores, pues todo lo consideran "puro juego", "sin compromiso" ni "responsabilidad". Según ellas, "les gusta lo fácil”, "sin hacer nada". En síntesis, "no estudian ni trabajan”, y a algunas personas las tachan de "delincuentes" y "vándalos". 
Revista Iberoamericana

de las Ciencias Sociales y Humanísticas

En cuanto a las percepciones positivas o neutras, los jóvenes opinan que la juventud es una etapa de "conocimiento" y "aprendizaje", donde las personas se interesan más por el medio ambiente y están más deseosas de actuar. Una joven añade que "hay de todo" en esta generación, la cual vive en "una época difícil", "limitada por el entorno".

Una perspectiva similar es percibida por los adultos, quienes asocian a ese grupo las palabras "aprender", "libertad", "conciencia en el medio ambiente" y "entusiasmo". En resumen, creen que es un grupo "variado", que tiene "más retos y menos oportunidades laborales y escolares", aunque todo "depende del contexto", en el cual los "padres" y la "familia" juegan un papel trascendente. Varias de estas visiones concuerdan con la bibliografía revisada y comentada.

\section{¿Qué es para usted ser joven?}

En contraste con lo visto en el apartado anterior, se puede decir que predomina una visión positiva, un poco más acentuada en las juventudes (tabla 2). En otras palabras, la juventud está mal, pero para mí ser joven es bueno porque ofrece aprendizaje y diversión.

Tabla 2. Qué es para usted ser joven

\begin{tabular}{|l|c|c|c|c|}
\hline & \multicolumn{2}{|c|}{$18-29$} & \multicolumn{2}{c|}{+40} \\
\hline & HOMBRES & MUJERES & HOMBRES & MUJERES \\
\hline Negativa & 0 & 2 & 2 & 0 \\
\hline Positiva & 16 & 14 & 11 & 13 \\
\hline $\begin{array}{l}\text { Negativa } \\
\text { positiva }\end{array}$ & 0 & 0 & 3 & 7 \\
\hline $\begin{array}{l}\text { Neutra } \\
\text { Totales }\end{array}$ & 4 & 4 & 4 & 0 \\
\hline TOTAL & & 20 & 20 & 20 \\
\hline
\end{tabular}

Fuente: Elaboración propia

Si se comparan las tablas 1 y 2 , se puede indicar que hay una diferencia entre la visión general (vista desde afuera) y personal (vista desde adentro) de la juventud. Es decir, el discurso de lo percibido y el discurso de lo vivido es diferente. En efecto, en esta segunda 


\section{Revista Iberoamericana de las Ciencias Sociales y Humanísticas}

interrogante se puede ver que ser joven es una oportunidad para "aprender", "estudiar", "descubrir" y "formar el rumbo al que vas". Las "experiencias" también son señaladas por los hombres jóvenes, así como "crecer", "prepararse”, “crear el futuro”, “construyendo", "proyectos", todo ello en función de formarse para el porvenir. Como lo explican algunos autores, constituye una etapa de formación a nivel psicológico y escolar (Erickson, 1972).

También se destaca — más para las mujeres - la importancia de la "energía” y "vitalidad" con que se cuenta, así como la "libertad". Esto se relaciona con lo señalado por Beck (2006), quien apunta que la juventud de hoy son los "hijos de la libertad" (salvando las distancias en relación con el significado más político del término). Tanto hombres como mujeres remarcan la "oportunidad para hacer lo que quieres", las "posibilidades de hacer varias cosas" y "cosas que te gustan", aunque ellos parecen más preocupados por formarse y hacer, y ellas por las capacidades con que se cuentan. Donde ambos sexos coindicen es en la posibilidad de "divertirse" y "disfrutar"; algunos incluso añaden que "sin obligaciones", ya que hay "tiempo libre" y se pueden "hacer cosas que más adelante no vas a poder hacer", como también indican Beck y Beck-Gernsheim (2003). Solo pocas personas de este grupo respondieron refiriéndose a aspectos formales o señalando que era una "etapa normal", en la cual todos tenían "las mismas características".

Pasando a la mirada positiva de la población adulta en cuanto a ser joven, resaltaron palabras como "aprender", “estudiar", "formarse", lo cual demuestra un acuerdo intergeneracional. Un hombre añadió que es una etapa para "aprender de los errores" y "madurar"; otros señalaron el "tener sueños", "ganas de salir adelante", "deseos de progresar".

Las mujeres adultas también se refieren a los "sueños", "metas", "proyectos" e incluso "comerse el mundo". De forma general, ambos sexos vinculan a la juventud con "alegría” y "disfrutar de la vida", y ellas añaden que es una "etapa hermosa" y "lo más bonito”. Estas últimas expresiones son asociadas con un paraíso construido en el discurso de la memoria histórica o biográfica (Halbwachs, 2004). En esa etapa también resulta valorada la "energía" y la "fuerza", ya que es posible realizar "infinidad de actividades" y "cosas que después ya no se pueden hacer".

Otras respuestas estuvieron más relacionadas con un tono neutro o descriptivo. A continuación, se ofrece un panorama más amplio de lo expresado (tabla 3). 
Revista Iberoamericana

de las Ciencias Sociales y

Humanísticas

ISSN: $2395-7972$

Tabla 3. Cómo ve usted a la juventud hoy y qué es para usted ser joven

\begin{tabular}{|c|c|c|c|c|}
\hline & Cómo ve usted a la & uventud hoy & Qué es para usted & ser joven \\
\hline $18-29$ & HOMBRES & MUJERES & HOMBRES & MUJERES \\
\hline \multirow[t]{9}{*}{ POSITIVAS } & $\begin{array}{l}\text { Conocimiento, } \\
\text { aprendizaje. }\end{array}$ & Interés en estudio & Aprender, estudiar & $\begin{array}{l}\text { Enseñanzas, } \\
\text { aprender, } \\
\text { descubrimientos, } \\
\text { formar el rumbo } \\
\text { al que vas }\end{array}$ \\
\hline & $\begin{array}{l}\text { Más despiertas en } \\
\text { cosas sociales, } \\
\text { exige. }\end{array}$ & $\begin{array}{l}\text { Papel importante } \\
\text { en los problemas } \\
\text { como medio } \\
\text { ambiente. }\end{array}$ & $\begin{array}{l}\text { Experiencias, } \\
\text { crecer, prepararse } \\
\text { para el futuro, } \\
\text { crear el futuro, } \\
\text { crearse como } \\
\text { persona, te estás } \\
\text { construyendo, } \\
\text { proyectos, } \\
\text { realizarte }\end{array}$ & $\begin{array}{l}\text { Energía cuerpo } \\
\text { y mente, } \\
\text { vitalidad, vivir }\end{array}$ \\
\hline & $\begin{array}{l}\text { Más abierta, } \\
\text { pensamientos } \\
\text { liberales, } \\
\text { experimentar, } \\
\text { relaciones sexuales }\end{array}$ & Libertad. & $\begin{array}{l}\text { Oportunidad para } \\
\text { hacer lo que } \\
\text { quieres, } \\
\text { posibilidades de } \\
\text { hacer varias } \\
\text { cosas, hacer cosas } \\
\text { que te gustan, } \\
\text { emprender }\end{array}$ & Libre \\
\hline & $\begin{array}{l}\text { Presente, dispuesta, } \\
\text { emprender, crecer }\end{array}$ & $\begin{array}{l}\text { Deseosa de hacer } \\
\text { muchas cosas, } \\
\text { iniciativa. }\end{array}$ & $\begin{array}{l}\text { Energía, } \\
\text { disposición ante la } \\
\text { vida, vivir al } \\
\text { máximo, activo }\end{array}$ & $\begin{array}{l}\text { Experiencias, } \\
\text { nuevas, muchas } \\
\text { experiencias }\end{array}$ \\
\hline & & & $\begin{array}{l}\text { Ayudar a cambiar } \\
\text { lo que se pueda, } \\
\text { generar cambios y } \\
\text { nuevas ideas, } \\
\text { rebelarse }\end{array}$ & $\begin{array}{l}\text { Hacer muchas } \\
\text { cosas, cosas que } \\
\text { te gustan, tomar } \\
\text { decisiones }\end{array}$ \\
\hline & & & $\begin{array}{l}\text { Libertades, ser } \\
\text { libre }\end{array}$ & $\begin{array}{l}\text { Divertirse, } \\
\text { disfrutar, dejarse } \\
\text { llevar, llevarla } \\
\text { tranquila con } \\
\text { amigos, salir }\end{array}$ \\
\hline & & & $\begin{array}{l}\text { Divertirse, } \\
\text { disfrutar }\end{array}$ & $\begin{array}{l}\text { Disfrutar la vida } \\
\text { sin tantas } \\
\text { obligaciones }\end{array}$ \\
\hline & & & Tiempo libre & \\
\hline & & & $\begin{array}{l}\text { Hacer cosas que } \\
\text { más adelante no } \\
\text { vas a poder hacer }\end{array}$ & \\
\hline MATIZADAS & & & & \\
\hline
\end{tabular}




\section{Revista lberoamericana de las Ciencias Sociales y Humanísticas}

\begin{tabular}{|c|c|c|c|c|}
\hline \multicolumn{5}{|l|}{$\begin{array}{l}\text { (neutras, } \\
\text { definiciones, } \\
\text { entorno) }\end{array}$} \\
\hline & & Hay de todo. & $\begin{array}{l}\text { Etapa normal que } \\
\text { pasamos, una } \\
\text { etapa }\end{array}$ & Una edad \\
\hline & & $\begin{array}{l}\text { Limitada por el } \\
\text { entorno, periodo } \\
\text { complicado por el } \\
\text { entorno. }\end{array}$ & $\begin{array}{l}\text { La edad no es solo } \\
\text { un número }\end{array}$ & $\begin{array}{l}\text { Un grupo de } \\
\text { personas con las } \\
\text { mismas } \\
\text { características }\end{array}$ \\
\hline & & $\begin{array}{l}\text { Época más difícil } \\
\text { que generaciones } \\
\text { pasadas. }\end{array}$ & & $\begin{array}{l}\text { Más que edad, } \\
\text { muchas formas } \\
\text { de definir ser } \\
\text { joven }\end{array}$ \\
\hline & & $\begin{array}{l}\text { Falta de dinero y } \\
\text { falta de empleo. }\end{array}$ & & \\
\hline \multicolumn{5}{|l|}{ NEGATIVAS } \\
\hline & $\begin{array}{l}\text { Perdida, sin rumbo, } \\
\text { errática, } \\
\text { desorientada, } \\
\text { desubicada, } \\
\text { distraída, dispersa, } \\
\text { confundida } \\
\end{array}$ & $\begin{array}{l}\text { Desubicada, } \\
\text { desenfocada, } \\
\text { dispersa, } \\
\text { confundida, no } \\
\text { saben lo que } \\
\text { quieren. } \\
\end{array}$ & & \\
\hline & $\begin{array}{l}\text { Indecisa, no saben } \\
\text { qué quieren. }\end{array}$ & \begin{tabular}{|l|} 
Poco soñadora, \\
desilusionada, \\
desmotivada \\
\end{tabular} & & \\
\hline & $\begin{array}{l}\text { Fuera de la realidad, } \\
\text { escape de la } \\
\text { realidad. }\end{array}$ & $\begin{array}{l}\text { Desinteresada, no } \\
\text { les importa nada. }\end{array}$ & & \\
\hline & $\begin{array}{l}\text { Sin motivación, sin } \\
\text { ganas de salir } \\
\text { adelante, no saben } \\
\text { qué les espera. }\end{array}$ & $\begin{array}{l}\text { Despreocupada, } \\
\text { no piensan antes } \\
\text { de actuar, no } \\
\text { actúan hasta que } \\
\text { algo les afecta. }\end{array}$ & & \\
\hline & $\begin{array}{l}\text { No piensan } \\
\text { consecuencias de } \\
\text { sus actos. }\end{array}$ & $\begin{array}{l}\text { La tecnología los } \\
\text { desconecta de la } \\
\text { familia. }\end{array}$ & & \\
\hline & $\begin{array}{l}\text { Indiferente, les vale } \\
\text { lo que hacen, } \\
\text { desinteresada, } \\
\text { despreocupada }\end{array}$ & Materialista. & & \\
\hline & Convenencieros. & Un poco mal. & & \\
\hline & $\begin{array}{l}\text { Sin valores, sin } \\
\text { respeto a la familia }\end{array}$ & Desesperada. & & \\
\hline & Rebelde. & & & \\
\hline & Vicios, alcohol. & & & \\
\hline
\end{tabular}


Revista lberoamericana

de las Ciencias Sociales y Humanísticas

ISSN: $2395-7972$

\begin{tabular}{|c|c|c|c|c|}
\hline & $\begin{array}{l}\text { Pésima, } \\
\text { descontrolada, } \\
\text { descarriada, podrida }\end{array}$ & & & \\
\hline+40 & HOMBRES & MUJERES & HOMBRES & MUJERES \\
\hline \multirow[t]{9}{*}{ POSITIVAS } & $\begin{array}{l}\text { Ganas aprender, } \\
\text { salir adelante. }\end{array}$ & Libertad. & $\begin{array}{l}\text { Aprender, } \\
\text { estudiar. }\end{array}$ & $\begin{array}{l}\text { Aprender, } \\
\text { formarte. }\end{array}$ \\
\hline & Más liberales. & Desenvuelta. & $\begin{array}{l}\text { Aprender errores, } \\
\text { madurar, } \\
\text { conocerse, crecer. }\end{array}$ & $\begin{array}{l}\text { Fuerza, } \\
\text { vitalidad, } \\
\text { iniciativa, } \\
\text { entusiasta. }\end{array}$ \\
\hline & $\begin{array}{l}\text { Más libertad } \\
\text { (fumar, relaciones } \\
\text { sexuales). }\end{array}$ & $\begin{array}{l}\text { Conciencia del } \\
\text { medio ambiente. }\end{array}$ & $\begin{array}{l}\text { Tener sueños, } \\
\text { deseos de } \\
\text { progresar, ganas } \\
\text { de salir adelante, } \\
\text { enfrentar lo que se } \\
\text { presente, } \\
\text { entusiasmo. }\end{array}$ & $\begin{array}{l}\text { Sueños, metas, } \\
\text { oportunidades, } \\
\text { ganas de hacer } \\
\text { muchas cosas, } \\
\text { proyectos, } \\
\text { comerte el } \\
\text { mundo. }\end{array}$ \\
\hline & $\begin{array}{l}\text { Despierta, } \\
\text { entusiasta. }\end{array}$ & Bien. & $\begin{array}{l}\text { Alegría, disfrutar } \\
\text { de la vida, } \\
\text { divertirse. }\end{array}$ & $\begin{array}{l}\text { Hermoso, etapa } \\
\text { hermosa, lo más } \\
\text { bonito, época } \\
\text { muy bonita }\end{array}$ \\
\hline & & & $\begin{array}{l}\text { Convivir, } \\
\text { socializar, salir de } \\
\text { fiesta. }\end{array}$ & $\begin{array}{l}\text { Disfrutar, } \\
\text { pasarla bien, lo } \\
\text { bueno de la } \\
\text { vida, vivir la } \\
\text { vida. }\end{array}$ \\
\hline & & & $\begin{array}{l}\text { Pocas } \\
\text { obligaciones, no } \\
\text { importa nada. }\end{array}$ & Apoyo familiar. \\
\hline & & & $\begin{array}{l}\text { Energía, cuerpo } \\
\text { fuerte }\end{array}$ & $\begin{array}{l}\text { Nuevas } \\
\text { experiencias, te } \\
\text { vas } \\
\text { independizando. }\end{array}$ \\
\hline & & & $\begin{array}{l}\text { Infinidad de } \\
\text { actividades, } \\
\text { aprovechar el } \\
\text { tiempo }\end{array}$ & \\
\hline & & & $\begin{array}{l}\text { Hacer cosas que } \\
\text { después ya no se } \\
\text { pueden. }\end{array}$ & \\
\hline $\begin{array}{l}\text { MATIZADAS } \\
\text { (neutras, } \\
\text { definiciones, } \\
\text { entorno) }\end{array}$ & & & & \\
\hline
\end{tabular}


Revista Iberoamericana

de las Ciencias Sociales y Humanísticas

ISSN: 2395 - 7972

\begin{tabular}{|c|c|c|c|c|}
\hline & $\begin{array}{l}\text { Variada, más retos } \\
\text { y menos } \\
\text { oportunidades } \\
\text { laborales y } \\
\text { escolares, las cosas } \\
\text { más complicadas. }\end{array}$ & $\begin{array}{l}\text { De todo un poco, } \\
\text { hay de todo, mitad } \\
\text { y mitad. }\end{array}$ & Estado mental. & \\
\hline & $\begin{array}{l}\text { Simplemente son } \\
\text { jóvenes, siempre ha } \\
\text { sido lo mismo. }\end{array}$ & $\begin{array}{l}\text { Depende del } \\
\text { contexto }\end{array}$ & Etapa vida. & \\
\hline & & $\begin{array}{l}\text { Si padres trabajan } \\
\text { los descuidan. }\end{array}$ & & \\
\hline & & $\begin{array}{l}\text { Si familia } \\
\text { enseñara valores } \\
\text { serían educados. }\end{array}$ & & \\
\hline \multicolumn{5}{|l|}{ NEGATIVAS } \\
\hline & $\begin{array}{l}\text { Perdida en la } \\
\text { tecnología, metida } \\
\text { en el mundo digital, } \\
\text { solo están en su } \\
\text { celular, utilizan mal } \\
\text { los medios, no ven } \\
\text { el punto de vista } \\
\text { real, solo de las } \\
\text { redes, alejada de la } \\
\text { realidad, }\end{array}$ & $\begin{array}{l}\text { Falta de } \\
\text { educación, mal } \\
\text { educados, no } \\
\text { hacen caso a } \\
\text { autoridades, no } \\
\text { respetan a los } \\
\text { mayores, sin } \\
\text { valores. }\end{array}$ & $\begin{array}{l}\text { No consciente } \\
\text { consecuencia de } \\
\text { tus acciones, } \\
\text { decisiones que } \\
\text { impactan tu vida. }\end{array}$ & $\begin{array}{l}\text { Hacer cosas sin } \\
\text { pensar, no } \\
\text { experiencia para } \\
\text { actuar con } \\
\text { madurez. }\end{array}$ \\
\hline & $\begin{array}{l}\text { Confundida, } \\
\text { desordenada, } \\
\text { distraída, siguen } \\
\text { modas. }\end{array}$ & $\begin{array}{l}\text { Falta interés, } \\
\text { desgana. }\end{array}$ & Dudas, desafíos. & $\begin{array}{l}\text { Problemas de } \\
\text { adicciones. }\end{array}$ \\
\hline & $\begin{array}{l}\text { Falta de conciencia, } \\
\text { falta de } \\
\text { preocupación, todo } \\
\text { se lo toman a la } \\
\text { ligera, todo les } \\
\text { parece fácil. }\end{array}$ & $\begin{array}{l}\text { Todo es puro } \\
\text { juego, pura } \\
\text { diversión, sin } \\
\text { compromiso, sin } \\
\text { responsabilidad. }\end{array}$ & Descontrol. & \\
\hline & $\begin{array}{l}\text { Flojos, no quieren } \\
\text { hacer nada, sienten } \\
\text { que merecen todo y } \\
\text { no hacen esfuerzo. }\end{array}$ & $\begin{array}{l}\text { No aprovechan } \\
\text { oportunidades, no } \\
\text { ganas de } \\
\text { superarse, lo } \\
\text { quieren todo fácil, } \\
\text { les gusta la vida } \\
\text { fácil, sin hacer } \\
\text { nada. }\end{array}$ & $\begin{array}{l}\text { Falta de } \\
\text { oportunidades. }\end{array}$ & \\
\hline & $\begin{array}{l}\text { Egoístas, yo y solo } \\
\text { yo. }\end{array}$ & $\begin{array}{l}\text { Desubicada, } \\
\text { desorientada }\end{array}$ & & \\
\hline & $\begin{array}{l}\text { Falta de valores, no } \\
\text { respetan. }\end{array}$ & Mal, mal camino & & \\
\hline
\end{tabular}


Revista Iberoamericana

de las Ciencias Sociales y

Humanísticas

ISSN: 2395 - 7972

\begin{tabular}{|l|l|l|l|l|}
\hline & $\begin{array}{l}\text { Mal educada, sin } \\
\text { educación, } \\
\text { groseros, } \\
\text { impertinentes. }\end{array}$ & $\begin{array}{l}\text { Alterada, } \\
\text { acelerada, } \\
\text { desatada }\end{array}$ & & \\
\hline & $\begin{array}{l}\text { Sin trabajo, sin } \\
\text { estudio. }\end{array}$ & $\begin{array}{l}\text { No estudian, no } \\
\text { trabajan }\end{array}$ & & \\
\hline & $\begin{array}{l}\text { Descarriada, } \\
\text { corrompida, } \\
\text { pervertida, } \\
\text { libertinaje }\end{array}$ & & \\
\hline Toman. & $\begin{array}{l}\text { Delincuentes, } \\
\text { vándalos, vagos, } \\
\text { roban. }\end{array}$ & & \\
\hline
\end{tabular}

Fuente: Elaboración propia

\section{¿Qué problemas tiene ser joven?}

Tras la autodefinición y esbozo de cómo se ve la juventud y qué es ser joven, a continuación se presentan los resultados en torno a los problemas y las ventajas de la juventud.

Para el grupo de jóvenes varones, las principales problemáticas se relacionan con las "dudas en el futuro" o el "no saber lo que se quiere hacer", la "crisis de identidad" o "existencial" y la "incertidumbre", lo cual se vincula con temores e inseguridades presentes y futuras. Igualmente, indican el ser "inexpertos", no estar "preparados" y "no ser tomados en serio", así como la "falta de dinero" y en ser "dependiente" (esto último referido por igual en ambos sexos). También les preocupa "pensar que la vida es fácil" y "no saber de los límites", o el "alejarse de las formas de pensar establecidas".

Las mujeres jóvenes, en cambio, hacen más hincapié en asuntos como "no mides las consecuencias" y te "equivocas" o cometes "errores", además de la "poca experiencia" y el no ser "tomada en serio", asuntos asociados a factores emocionales y a experiencias vividas. También subrayan la "falta de trabajo" y el no tener "estudios". Igualmente, le preocupan los "riesgos" y las "adicciones" a "drogas", "alcohol" y hasta "relaciones tóxicas"; asimismo, la "violencia", la "depresión" y el "suicidio", cuestiones que parecen estar aumentando en la realidad cotidiana del país en los últimos años, por lo que deben ser tomadas en cuenta.

Sobre los problemas que expone la población adulta, los hombres parecen más preocupados por la "falta de oportunidades" laborales y escolares, así como la "falta de experiencia" en el sentido de cometer "errores", de sentir "inseguridad" y de ser "juzgados". 


\section{Revista Iberoamericana de las Ciencias Sociales y Humanísticas}

Un tema que les preocupa mucho es no tener estudios ni trabajo, temor que se vincula con el rol de proveedor. Asimismo, apuntan que los jóvenes pasan mucho tiempo en internet y en las redes sociales, que carecen de "límites” y “orientación”, con lo cual caen en problemáticas como "embarazo", “droga", "alcoholismo", "vicios". Incluso señalan el "no respeto a los padres" y que "se les hacen fáciles las cosas", "no escuchan", "creen saberlo todo" y "creen que los adultos no entienden”.

Las mujeres mayores señalan la falta de "experiencia", por lo que pueden ser "vulnerables" y "dejarse llevar". Para ellas, esto se debe a que "no escuchan a sus mayores" y son "desobedientes". También se refieren a la carencia de "oportunidades de empleo", aunque apuntan que "no aprovechan las oportunidades", son "flojos" y se "les hace un problema todo", y también indican lo referido a "adicciones" y "drogas. Incluso les preocupa que muchos problemas de esa generación se proceden en familias disfuncionales, a lo cual se debe que en la escuela no les ponen atención y las autoridades abusan. Con esta observación enmarcan el problema en el contexto y en la sociedad actual.

\section{¿Qué ventajas tiene ser joven?}

En cuanto a las ventajas, los jóvenes hombres se refieren a "aprender", "saber", “conocer", y luego a las "experiencias". También destacan la "capacidad de hacer muchas cosas" y las "miles de oportunidades", así como la "energía" y el "interés" o el "tiempo libre". Asimismo, destacan la "poca responsabilidad", el "divertirse y disfrutar", las “oportunidades laborales y escolares" y el poder trascender, en el sentido de "dejar huella, defender propuestas, mejorar las condiciones de su generación”. Ellos asocian como ventaja el aprendizaje y la experiencia, lo cual puede impactar en el mejoramiento social y en las oportunidades de educación y empleo.

Las mujeres jóvenes abordan temas similares, pero en distinto orden de prioridad. Para ellas, la primordial ventaja es la "libertad" junto a la "no responsabilidad", el tener “tiempo" y también el "aprender" (esto último, no como lo más importante, lo cual sí fue señalado por hombres jóvenes). También se refieren al "hacer muchas cosas", la "vitalidad", el tener "experiencias", el "disfrutar" y el "socializar", cuestión que con otras palabras apareció en alguna ocasión y que se trata de una forma lúdica de intercambio social (Urteaga, 2011). Del mismo modo, se refieren a la "labor social, nuevas ideas, frescas, reivindicar cosas, mover el mundo, cambiar lo que está mal", lo cual se asocia con el dejar huella. En 


\section{Revista Iberoamericana \\ de las Ciencias Sociales y Humanísticas}

ISSN: $2395-7972$

este sentido, para ambos sexos el cambiar el estado de las cosas para mejorar la sociedad está presente en sus relatos sobre las ventajas de ser joven.

Por otra parte, y según la población adulta, tanto para hombres como para mujeres las "oportunidades" que tiene la juventud es la ventaja más importante y destacada. Según estas personas, se destacan las oportunidades de "hacer muchas cosas", "todo lo puedes hacer", "no hay límites", "todo lo que quieras", incluso estudiar y trabajar. Luego aparece la valoración de la "energía" y la "fuerza", aspectos vinculados con la "salud". A los hombres adultos les llama la atención la "motivación” y las "ganas de salir adelante", lo cual se asocia a frases sobre "expectativas", "sueños” y “entusiasmo", así como el "disfrutar" y el no tener "responsabilidades" ni "compromisos", mientras que las mujeres destacan el ser "libres. A continuación, se ofrece un panorama más preciso sobre los problemas y ventajas de ser jóvenes:

Tabla 4. Problemas y ventajas tiene el ser joven

\begin{tabular}{|c|c|c|c|c|}
\hline & \multicolumn{2}{|c|}{ PROBLEMAS } & \multicolumn{2}{|c|}{ VENTAJAS } \\
\hline $18-29$ & HOMBRES & MUJERES & HOMBRES & MUJERES \\
\hline & $\begin{array}{l}\text { Dudas futuro, no } \\
\text { saber lo que se } \\
\text { quiere hacer. }\end{array}$ & $\begin{array}{l}\text { No mides las } \\
\text { consecuencias, } \\
\text { equivocas } \\
\text { decisiones, errores } \\
\text { generacionales, } \\
\text { dejarse llevar. }\end{array}$ & $\begin{array}{l}\text { Aprender, saber, } \\
\text { conocer, } \\
\text { información. }\end{array}$ & Libertad. \\
\hline & $\begin{array}{l}\text { Crisis identidad, } \\
\text { existencial, } \\
\text { autoaceptación, } \\
\text { resiliencia. }\end{array}$ & $\begin{array}{l}\text { No experiencia, } \\
\text { poca experiencia, } \\
\text { no te toman en } \\
\text { serio, te critican. }\end{array}$ & Experiencias. & $\begin{array}{l}\text { No } \\
\text { responsabilidades. }\end{array}$ \\
\hline & $\begin{array}{l}\text { Incertidumbre en el } \\
\text { trabajo y el estudio } \\
\text { (exámenes, tareas). }\end{array}$ & $\begin{array}{l}\text { Faltan } \\
\text { oportunidades, no } \\
\text { puedes hacer } \\
\text { cosas. }\end{array}$ & $\begin{array}{l}\text { Capacidad de } \\
\text { hacer muchas } \\
\text { cosas, miles de } \\
\text { oportunidades, } \\
\text { trabajar en } \\
\text { cualquier cosa, } \\
\text { lograr lo que te } \\
\text { propongas, } \\
\text { cumplir sueños. }\end{array}$ & Tiempo. \\
\hline & $\begin{array}{l}\text { Falta dinero, } \\
\text { economía, ingreso, } \\
\text { ser dependientes. }\end{array}$ & $\begin{array}{l}\text { Falta dinero, } \\
\text { economía, } \\
\text { dependiente. }\end{array}$ & $\begin{array}{l}\text { Energía, actitud, } \\
\text { pasión, interés. }\end{array}$ & Aprender. \\
\hline
\end{tabular}


Revista lberoamericana

de las Ciencias Sociales y Humanísticas

ISSN: 2395 - 7972

\begin{tabular}{|c|c|c|c|c|}
\hline & $\begin{array}{l}\text { Sin experiencia, } \\
\text { inexpertos, no } \\
\text { preparado, no } \\
\text { toman en serio. }\end{array}$ & No estudios. & $\begin{array}{l}\text { Libertad, tomas } \\
\text { tus propias } \\
\text { decisiones, } \\
\text { alejarte de los } \\
\text { padres. }\end{array}$ & $\begin{array}{l}\text { Hacer muchas } \\
\text { cosas, ganas hacer } \\
\text { mucho. }\end{array}$ \\
\hline & $\begin{array}{l}\text { No saber límites, } \\
\text { pensar que la vida } \\
\text { es fácil. }\end{array}$ & Falta trabajo. & Tiempo libre. & $\begin{array}{l}\text { Vitalidad, } \\
\text { rendimiento físico } \\
\text { e intelectual. }\end{array}$ \\
\hline & Incomprendidos. & $\begin{array}{l}\text { Existenciales, } \\
\text { búsqueda. }\end{array}$ & $\begin{array}{l}\text { Poca o ninguna } \\
\text { responsabilidad. }\end{array}$ & Experiencias. \\
\hline & Socializar. & Egoísmo. & \begin{tabular}{|l} 
Divertirse, \\
disfrutar
\end{tabular} & Disfrutar. \\
\hline & $\begin{array}{l}\text { Alejarse de las } \\
\text { formas de pensar } \\
\text { establecidas. }\end{array}$ & Desinterés. & $\begin{array}{l}\text { Oportunidades } \\
\text { laborales y } \\
\text { escolares. } \\
\end{array}$ & Socializar. \\
\hline & & $\begin{array}{l}\text { Libertinajes, } \\
\text { riesgos. }\end{array}$ & $\begin{array}{l}\text { Dejar huella, } \\
\text { defender } \\
\text { propuestas, } \\
\text { mejorar } \\
\text { condiciones de su } \\
\text { generación. }\end{array}$ & Mente abierta. \\
\hline & & $\begin{array}{l}\text { Adicciones, } \\
\text { drogas, alcohol, } \\
\text { relaciones tóxicas. }\end{array}$ & & $\begin{array}{l}\text { Labor social, } \\
\text { nuevas ideas, } \\
\text { frescas, reivindicar } \\
\text { cosas, mover el } \\
\text { mundo, cambiar lo } \\
\text { que está mal. }\end{array}$ \\
\hline & & Violencia. & & \\
\hline & & $\begin{array}{l}\text { Falta presencia } \\
\text { padres. }\end{array}$ & & \\
\hline & & $\begin{array}{l}\text { Depresión, } \\
\text { suicidio. }\end{array}$ & & \\
\hline No & $\begin{array}{l}\text { Ninguno, no hay, la } \\
\text { mejor etapa, el } \\
\text { poder hacer todo. }\end{array}$ & & & \\
\hline+40 & $\begin{array}{l}\text { Falta de } \\
\text { oportunidades } \\
\text { laborales } \\
\text { (salariales) y } \\
\text { escolares. }\end{array}$ & $\begin{array}{l}\text { Sin experiencia, se } \\
\text { dejan llevar, } \\
\text { vulnerables, falta } \\
\text { madurez, no } \\
\text { preparados. }\end{array}$ & \begin{tabular}{|l} 
Más \\
oportunidades, \\
sinnúmero de \\
oportunidades, \\
puedes hacer \\
muchas cosas, \\
todo lo puedes \\
hacer, no límites, \\
hacer lo que \\
quieras. \\
\end{tabular} & $\begin{array}{l}\text { Oportunidades en } \\
\text { estudio y trabajo, } \\
\text { becas, tecnologías, } \\
\text { poder estudiar, } \\
\text { prepararse para ser } \\
\text { alguien. }\end{array}$ \\
\hline
\end{tabular}


Revista Iberoamericana

de las Ciencias Sociales y Humanísticas

ISSN: $2395-7972$

\begin{tabular}{|c|c|c|c|c|}
\hline & $\begin{array}{l}\text { Falta de } \\
\text { experiencia, } \\
\text { madurez, errores, } \\
\text { inseguridad, te } \\
\text { juzgan. }\end{array}$ & $\begin{array}{l}\text { No escuchan a los } \\
\text { mayores, } \\
\text { desobedientes. }\end{array}$ & $\begin{array}{l}\text { Energía, fuerza, } \\
\text { vitalidad, } \\
\text { agilidad. }\end{array}$ & Salud. \\
\hline & $\begin{array}{l}\text { Mucho tiempo en } \\
\text { las redes, provoca } \\
\text { enfermedades y que } \\
\text { no te comprendan. }\end{array}$ & $\begin{array}{l}\text { No oportunidades } \\
\text { de empleo. }\end{array}$ & $\begin{array}{l}\text { Motivación, ganas } \\
\text { de salir adelante } \\
\text { trabajando o } \\
\text { estudiando, } \\
\text { expectativas, } \\
\text { sueños, } \\
\text { entusiasmo. }\end{array}$ & $\begin{array}{l}\text { Energía, fuerza, } \\
\text { agilidad, } \\
\text { entusiasmo. }\end{array}$ \\
\hline & $\begin{array}{l}\text { No límites y no } \\
\text { orientación: } \\
\text { embarazo, droga, } \\
\text { alcoholismo, vicios. }\end{array}$ & $\begin{array}{l}\text { No aprovechan las } \\
\text { oportunidades, no } \\
\text { aprovechan la } \\
\text { juventud. }\end{array}$ & Tiempo. & Tiempo. \\
\hline & $\begin{array}{l}\text { No respetan a los } \\
\text { padres. }\end{array}$ & $\begin{array}{l}\text { Flojos, se les hace } \\
\text { un problema todo. }\end{array}$ & $\begin{array}{l}\text { Conocer lugares y } \\
\text { personas. }\end{array}$ & $\begin{array}{l}\text { Hacer muchas } \\
\text { cosas. }\end{array}$ \\
\hline & $\begin{array}{l}\text { Se les hacen fáciles } \\
\text { las cosas, no } \\
\text { objetivo de vida. }\end{array}$ & $\begin{array}{l}\text { Adicciones, } \\
\text { drogas. }\end{array}$ & Disfrutar. & Libres. \\
\hline & $\begin{array}{l}\text { No escuchan, creen } \\
\text { saberlo todo, creen } \\
\text { que adultos no } \\
\text { entienden. }\end{array}$ & $\begin{array}{l}\text { Adultos cierran } \\
\text { puertas: Casa: no } \\
\text { hacen caso, } \\
\text { familias } \\
\text { disfuncionales. } \\
\text { Escuelas: no les } \\
\text { ponen atención. } \\
\text { Autoridades: } \\
\text { abusan. } \\
\end{array}$ & $\begin{array}{l}\text { No } \\
\text { responsabilidades. }\end{array}$ & No compromisos. \\
\hline & $\begin{array}{l}\text { Que los adultos los } \\
\text { escuchen. }\end{array}$ & & Ejercicio. & Ejercicio. \\
\hline & & & & Viajar. \\
\hline No & $\begin{array}{l}\text { No, ninguno, } \\
\text { normal, no hay, } \\
\text { depende de qué } \\
\text { sector. }\end{array}$ & $\begin{array}{l}\text { Más que } \\
\text { problemas son } \\
\text { experiencias para } \\
\text { aprender } \\
\end{array}$ & & \\
\hline
\end{tabular}

Fuente: Elaboración propia 


\section{Conclusiones}

La juventud es una época de la vida idealizada a la cual, sin embargo, también se le asocian una diversidad de problemas vinculados con la drogadicción y la delincuencia, así como con algunas actitudes de desinterés, apatía, consumismo, radicalismo, contestación, contracultura y marginalidad. Esto ha provocado que los jóvenes reproduzcan ese discurso social, el cual paradójicamente no asocian con ellos mismos, sino con "los otros" jóvenes, a los cuales se les ha querido ayudar usando políticas enfocadas en distraerlos y mantenerlos ocupados mediante actividades que parecieran relacionarse solo con esa etapa de la vida, es decir, deporte, cultura y recreación.

Sin embargo, la juventud es una etapa en la que también se presentan ventajas y problemas, los cuales son percibidos tanto por jóvenes como por adultos, como se ha demostrado en este trabajo. Por ejemplo, y en primer lugar, se puede decir que para un alto porcentaje de los consultados —independientemente de si son jóvenes o adultos, mujeres u hombres - la mayoría de la juventud actual está perdida y desorientada.

Aun así, al momento de consultar sobre la definición de ser joven aparecen expresiones sobre las oportunidades ante la vida presente y futura, lo cual se fundamenta en la posibilidad de aprender y formarse. En este sentido, el grupo de jóvenes hace hincapié en hacer cosas y tener energía, mientras que el de los adultos agrega palabras vinculadas con los sueños, la alegría y lo bonito (adjetivo usado por las mujeres), lo que deja entrever cierto grado de recuerdo y una suerte de melancolía por esa época.

El tercer elemento detectado se centra en los problemas del ser joven; estos se relacionan con aspectos personales-psicológicos y sociales-colectivos (es decir, lo material, lo mental y lo emocional). El grupo joven entrevistado hace énfasis en el temor y la incertidumbre (emociones insatisfactorias) y en la falta de oportunidades, principalmente laborales y educativas (realidades del contexto social). Por su parte, el sector de mayor edad subraya la falta de experiencia y de oportunidades de escuela y empleo (asuntos sociales materiales), así como cuestiones comportamentales o conductuales, pues no escuchan ni tienen respeto, lo que se puede deber a la ausencia de los progenitores.

En lo concerniente a las ventajas, los jóvenes aprecian el aprender, las experiencias y el hacer muchas cosas, mientras que los mayores valoran el hacer lo que se quiere y el tener más energía, así como las oportunidades educativas y de empleo, lo cual pareciera contrastar 


\section{Revista Iberoamericana \\ de las Ciencias Sociales y Humanísticas}

ISSN: $2395-7972$

con los problemas actuales en torno a la situación ocupacional, las responsabilidades y las obligaciones.

Finalmente, se cierra el texto con la transcripción directa de algunos participantes en esta investigación. Algunas opiniones resultan contradictorias, pero son una muestra de las ambivalencias que emergen en torno al concepto juventud. Por ejemplo, una mujer de 40 años expresó lo que para ella es ser joven: "Es una etapa en la vida hermosa, donde puedes decidir con tranquilidad y sabiduría a lo que te quieres dedicar en el futuro y donde puedes disfrutar con responsabilidad de casi todo". Otra de 68 años afirmó que es "la plenitud de la vida". En cambio, una joven de 18 años señaló que ve a la juventud “errática, como sin rumbo fijo" y otra opinó que la ve "un poco distraída e indecisa de lo que quiere". Dos enfoques diferentes, dos visiones de la juventud y de la vida misma que es aconsejable tener presentes. Asimismo, un joven de 22 años apunta: “Creo que está dividida, unos pocos tienen ganas de salir adelante y realmente emprender y crecer, pero la mayoría está muy desorientada y podrida", mientras que una joven de 21 años explica: "Están deseosos para hacer muchas cosas, pero limitada por su entorno, falta de dinero". Otra mujer de 48 años opinó: "Hay muchos jóvenes, depende de en qué contexto se desarrollen”, y también a algunos les parece "como un estado luminoso, el cuerpo y la mente están llenos de energía" (mujer de 21 años). Un hombre de 76 años considera que la juventud es "tener alegría, saber escuchar, aprovechar el tiempo, ser mejor y vivir mejor" y para una mujer de 48 años es una etapa de "mucha vitalidad, tienes ganas de hacer muchas cosas, te quieres comer el mundo".

\section{Futuras líneas de investigación}

Añadir que, por supuesto, no es una investigación cerrada y que es posible seguir ampliando la información y ahondando significados. Por ejemplo, el punto de la ambigüedad de la concepción misma de la juventud, idealizada y problematizada, anhelada y criticada, por las personas adultas consultadas y también por el grupo etario juvenil que participó en este trabajo. No solo eso, el hecho que los fenómenos se estudien desde la voz de la gente más allá de la reflexión especializada, es algo que hay que fomentar para aportar al conocimiento, y sobre todo y de manera especial, a la comprensión sociocultural, personal y colectiva, de las creencias y las prácticas, los discursos y las experiencias, que tanta falta hace en etapas vulnerables de la vida y en épocas inciertas de la existencia. 
Revista Iberoamericana

de las Ciencias Sociales y

Humanísticas

ISSN: $2395-7972$

\section{Referencias}

Ariès, P. (1962). Centuries of Childhood. A Social History of Family Life. New York, USA: Vintage Books.

Beck, U. y Beck-Gernsheim, E. (2003). La individualización. El individualismo institucionalizado y sus consecuencias sociales y políticas. Barcelona, España: Piados.

Beck, U. (2006). Hijos de la libertad: contra las lamentaciones por el derrumbe de los valores. En Beck, U. (coord.), Hijos de la libertad (pp. 7-34). Ciudad de México, México: FCE.

Bourdieu, P. (1984). Sociología y cultura. Ciudad de México, México: Grijalbo/CONACULTA.

Cardús, S. y Estruch, J. (1992). Les Enquestes a la Joventut a Catalunya. "Bells deliris fascinen la raó”. Barcelona, España: Generalitat de Catalunya.

Coleman, J. S. y Husén, T. (1989). Inserción de los jóvenes en una sociedad en cambio. Madrid, España: Narcea.

Consejo Nacional para Prevenir la Discriminación (Conapred) (2018). Personas jóvenes. Ciudad de México, México. Recuperado de http://www.conapred.org.mx/userfiles/files/FichaTematica_Jovenes.pdf

Consejo Nacional de Evaluación de la Política de Desarrollo Social (Conveval) (2018). Informe de la política de desarrollo social. Ciudad de México, México. Recuperado de https://www.coneval.org.mx/Evaluacion/IEPSM/IEPSM/Paginas/IEPDS2018.aspx

Duarte, K. (2000). ¿Juventud o juventudes? Acerca de cómo mirar y remirar a las juventudes en nuestro continente. Última Década, 8(13), 59-77.

Erikson, E. H. (1972). Sociedad y adolescencia. Ciudad de México, México: Siglo XXI.

Erikson, E. H. (1985). Identidad. Juventud y crisis. Madrid, España: Taurus.

Fernández, A.M. (2003). Cultura política y jóvenes en el umbral del nuevo milenio. Ciudad de México, México: IMJ/IFE.

Feixa, C. (1993). La joventut com a metàfora. Sobre les cultures juvenils. Barcelona, España: Generalitat de Catalunya.

Halbwachs, M. (2004). Los marcos de la memoria. Barcelona, España: Anthropos. 
Revista Iberoamericana

de las Ciencias Sociales y Humanísticas

ISSN: $2395-7972$

Hall, S. (1904). Adolescense: Its Psychology and it relations to Psychologi, Sociology, Sex, Crime, Religion and Education. New York, USA: Appleton Century Crofts.

Instituto Mexicano de la Juventud (IMJ) (2002). Encuesta Nacional de Juventud 2000. Ciudad de México, México: IMJ.

Instituto Mexicano de la Juventud (IMJ) (2017). ¿Qué es ser joven? Recuperado de Www.gob.mx/IMJUVE/articulos/que-es-ser- joven

Instituto Nacional de Estadística, Geografía e Información (Inegi) (2015). Encuesta intercensal 2015. Aguascalientes, México: INEGI. Recuperado de www.inegi.org.mx

Lechner, N. (2004). Cultura juvenil y desarrollo humano. Jóvenes. Revista de Estudios de la Juventud, 8(20), 12-27.

Lozano, J. M. (1991). De què parem quan parlem dels joves? Barcelona, España: Cristianisme i Justicia.

Margulis, M. y Urresti, M. (2008). La juventud es más que una palabra. En Margulis, M. (ed.), La juventud es más que una palabra (pp.14-16). Buenos Aires, Argentina: Biblos.

Martín Serrano, M. (1991). Los valores actuales de la juventud en España. Madrid, España: Instituto de la Juventud de España (INJUVE).

Martínez, R. y Berney, J. (1991). Enquesta a la Juventut de Catalunya 1990. Barcelona, España: Genralitat de Catalunya.

Mead, M. (1945). Adolescencia y cultura en Samoa. Buenos Aires, Argentina: Paidós.

Organización de las Naciones Unidas (ONU) (2020). Juventud. Recuperado de un.org/es/sections/issues-dpth/youth-o/index.html

Passerini, L. (1996). La juventud, metáfora de cambio social. (Dos debates sobre los jóvenes en la Italia fascista y en los Estados Unidos durante los años cincuenta). En Levi, G. y Schmitt, J. C. (coords.), Historia de los jóvenes (pp. 381-453). Madrid, España: Taurus.

Pérez, M. A. (2015). Estudio de los campos semánticos que sirven en la construcción de la unidad fraseológica del tipo peyorativo. Forma y función, 28(1), 157-182.

Reguillo, R. (1997). Culturas juveniles. Producir la identidad: un mapa de interacciones. Jóvenes. Revista de Estudios sobre la Juventud, 2(5), 12-31. 
Reguillo, R. (2010). La condición juvenil en México contemporáneo. Biografías, incertidumbres y lugares. En Reguillo, R. (coord.), Los jóvenes en México (pp. 395429). Ciudad de México, México: FCE/CONACULTA.

Rousseau, J. J. (1972). Emilio o la educación. Ciudad de México, México: Porrúa.

Salas, M. y De Oliveira, O. (2014). Desafíos y paradojas. Los jóvenes frente a las desigualdades sociales. Ciudad de México, México: COLMEX.

Sepúlveda, M. E. (2011). Del concepto de juventud al de juventudes y al de lo juvenil. Revista de Educación y Pedagogía, 23(60), 147-157.

Souto, S. (2007). Juventud, teoría e historia: la formación de un sujeto social y de un objeto de análisis. Historia Actual Online, (13), 171-192.

Ulloa, G. (2016). Tendencias epistémicas sobre la categoría juventud. Una perspectiva foucaultiana. Revista Ciencia Social, 29(38), 103-122.

Urteaga, M. (2011). La construcción juvenil de la realidad. Jóvenes mexicanos contemporáneos. Ciudad de México, México: UAM/JP.

Valenzuela, J. M. (2009). El futuro ya se fue. Socioantropología de l@s juventudes en la modernidad. Tijuana, México: COLEF.

Villa, M. E. (2011). Del concepto de juventud al de juventudes y al de lo juvenil. Revista de Educación y Pedagogía, 23(60), 147-157.

Welti, C. (1996). Compromisos para el futuro demográfico. En Cordera, R., Victoria, J. L. y Becerra, R. (coords.), México Joven. Población y propuestas para la discusión. Ciudad de México, México: UNAM. 